\title{
Aktif Karbon Destekli Nano Boyutlu Sıfır Değerlikli Demir ile Sulu Ortamlardan Fosfat Giderimi: Cevap Yüzey Yöntemi ile İşletme Parametrelerinin Optimizasyonu
}

\section{Phosphate Removal from Aqueous Solutions by Activated Carbon-Supported Nano-scale Zero-Valent Iron: Optimization of Operating Parameters by Response Surface Methodology}

\author{
Geliş / Received: 03/05/2019
}

\author{
Müslün Sara Tunç ${ }^{1 *}$
}

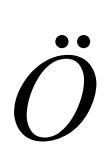

Revize / Revised: 24/07/2019

Kabul / Accepted: 05/08/2019

\begin{abstract}
z- Bu çalışmada, sulu faz borhidrür indirgeme metodu ile aktif karbon destekli nano boyutlu sıfır değerikli demir (AC-nZVI) partikülleri sentezlenmiş ve sentezlenen AC-nZVI partikülleri sulu ortamlardan fosfat gideriminde kullanılmıştır. Fosfat giderim verimi üzerinde çözelti pH'ı, AC-nZVI miktarı, başlangıç fosfat konsantrasyonu ve temas süresi işletme parametrelerinin etkilerini ve optimum şartları belirlemek için cevap yüzey metodu (CYM) uygulanmıştır. Deneysel dizaynda ve sonuçların analizinde merkezi kompozit dizaynı (MKD) kullanılmıştır. Varyans analizi (ANOVA) sonuçlarına göre, ikinci dereceden polinominal model istatistiksel olarak anlamı ı $(P=0.0002)$ ve determinasyon katsayısı $\left(R^{2}\right) 0.8735$ olarak bulunmuştur. AC-nZVI ile maksimum fosfat giderimi için optimum şartlar pH 3.09, AC-nZVI miktarı $0.59 \mathrm{~g} / \mathrm{L}$, fosfat konsantrasyonu $30.69 \mathrm{mg} \mathrm{P} / \mathrm{L}$ ve temas süresi 66.58 dakika olarak belirlenmiştir. Bu çalışmanın sonuçları, atıksulardan fosfat gideriminde AC-nZVI'nın etkili bir adsorbent olarak kullanılabileceğini göstermiştir.
\end{abstract}

Anahtar Kelimeler- Adsorpsiyon, Fosfat, AC-Nzvı, Optimizasyon, Cevap Yüzey Yöntemi.

A bstract- In this study, activated carbon-supported nano-scale zero-valent iron particles were synthesized by the aqueous phase borohydride reduction method and the synthesized AC-nZVI particles were used for the phosphate removal from aqueous solutions. The effects of the operating parameters that included $\mathrm{pH}, \mathrm{AC}$ nZVI amount, initial phosphate concentration and contact time on the phosphate removal were investigated using response surface methodology. The central composite design was employed for the experimental design and analysis of the results. According to results of variance analysis (ANOVA), the second order polynomial model was statistically significant $(P=0.0002)$ and determination coefficient $\left(R^{2}\right)$ was 0.8735 . The optimum conditions for phosphate removal by AC-nZVI were determined as $\mathrm{pH}$ of 3.09, AC-nZVI amount of $0.59 \mathrm{~g} / \mathrm{L}$, initial phosphate concentration of $30.69 \mathrm{mg}$ $\mathrm{P} / \mathrm{L}$ and contact time of 66.58 minutes. The results of this study demonstrated that AC-nZVI could be used as an effective adsorbent for phosphate removal from wastewater.

Keywords- Adsorption, Phosphate, AC-Nzvi, Optimization, Response Surface Methodology

\footnotetext{
1*Sorumlu yazar iletişim: saratunc@firat.edu.tr (https://orcid.org/0000-0001-9907-0428) Çevre Mühendisliği Bölümü, Mühendislik Fakültesi, Fırat Üniversitesi, Elazığ
} 


\section{I.GIRIŞ}

Fosfor, enerji taşınımı ve biyokütle büyümesine önemli katkı sağlayan temel bir elementtir. Tarımsal ve endüstriyel ürünler için de önemlidir [1]. Bitkiler için gerekli temel nutrientlerden biri olduğu için tarımsal amaçlı kullanılan gübrelerin ana bileşenini oluşturmaktadır [2].

Su kütlelerinde fosfor bileşiklerinin varlığı çeşitli kaynaklardan ileri gelmektedir. Fosfor bileşiklerinin doğal kaynakları toprak bileşenlerinin çözünmesi, organik maddenin ayrışması ve mikroorganizmaların hücresel olarak ayrışmasından ibarettir. Antropojenik kaynakları ise evsel ve endüstriyel atıklar, deterjanlar, hayvan dışkısı ve gübrelerdir [3].

Fosfor, sularda hem partiküler hem de çözünmüş formlarda bulunmaktadır. Fosforun alışıla gelmiş formları ortofosfatlar, polifosfatlar ve organik fosfatlardır [4]. Sularda fosforun fazla olması, bazı olası problemlere neden olmaktadır. Endüstrilerin proseslerinde kullanılan sularda aşırı fosfat bulunması borularda tıkanma sorununa yol açmaktadır [5]. Göl, nehir ve dere gibi su kütlelerine fazla miktarda fosforun ulaşması ötrofikasyona neden olmaktadır [6]. Su kütlelerinde ötrofikasyon tüm dünyada sorun haline gelmiştir [3]. Ötrofikasyon, toksik alg patlaması ve çözünmüş oksijenin tükenmesi ya da hipoksik bölgelerin gelişimi gibi zararlı ekolojik etkilere neden olmaktadır. Hem toksik alg patlaması hem de hipoksik bölgeler sucul canlılara zarar vermekte ve balık ölümlerine yol açabilmektedir. Su kütlelerinin ötrofikasyonu ayrıca bitki ve hayvan türleri kompozisyonunda değişime, biyolojik çeşitliliğin kaybına ve besin ağlarının bozulmasına da yol açabilmektedir [7]. Suların farklı amaçlar için kullanımında ciddi bir problem olmaktadır [3]. Hızlı gelişen ötrofikasyon, sadece sulardaki yaşamı etkilemekle kalmamakta, aynı zamanda sulardaki besinlere ve başka kaynaklara bağlı olan toplumların ekonomik gelişimlerini de dolaylı olarak engellemektedir. $0.02 \mathrm{mg} / \mathrm{L}$ çözünmüş fosfatın sularda bol miktarda alg büyümesine yol açabilecek potansiyele sahip olduğu düşünülmektedir [4]. Ötrofikasyondan doğal suları korumak için deşarjdan önce atıksulardan fosfat giderilmelidir [8]. Atıksulardan fosfat giderimi konusunda yürütülen çalışmalarda kimyasal çökelme [9], biyolojik arıtma [10] ve adsorpsiyon [2,6,11] gibi çeşitli arıtma prosesleri kullanılmıştır. Kimyasal çökelme fosfat gideriminde etkili bir yöntem olmakla birlikte bu yöntemin dezavantajı aşırı kimyasal reaktiflerin ve oluşan çamurun ikincil kirlenmeye neden olmasıdır. Biyolojik prosesin fosfor biriken bakterilere bağlı olduğu göz önüne alındığında, bu prosesler fosfat giderimi için kolayca optimize edilemeyebilir ve böylece biyolojik arıtma katı deşarj gereksinimlerini karşılayamayabilir [11]. Bu prosesler arasında adsorpsiyon, düşük maliyeti ve yüksek veriminden dolayı sulu ortamlardan fosfat gideriminde en etkili proseslerden biri olarak gösterilmiştir [12]. Demir oksitler [13], goetit (FeOOH) [14], aktif kırmızı çamur [15] ve aktif karbon [16] gibi sorbentler kullanılarak sulardan fosfat giderilebilmektedir. Ancak, bu sorbentlerle ilgili karşılaşılan sorunlardan biri düşük adsorpsiyon kapasitelerine sahip olmalarıdır [4].

Son zamanlarda, metaller, nütrientler, organik maddeler ve inorganikler gibi çeşitli kirleticilerin gideriminde nanopartiküller kullanılmaktadır. Nanopartiküller arasında, nano boyutlu sıfır değerlikli demir (nZVI) çok dikkat çekmektedir [17]. nZVI halojenli hidrokarbonlar [18], nitroaromatik bileşikler [19], antibiyotikler [20], boyarmaddeler [21] ve ağır metaller [22] gibi çeşitli kirleticilerin gideriminde etkili bir şekilde kullanılmıştır. Yüzey alanı, boyutu ve yüzey yükü gibi karakteristiklerinden dolayı nZVI partikülleri sorpsiyon prosesi için iyi adsorptif özellikler göstermektedir. Ancak, Van der Waalls ve manyetik kuvvetlerden dolayı nZVI partikülleri kümelenme eğilimindedir. nZVI'nın kümelenmesi yüzey alanlarını azaltmakta ve sorpsiyon kapasitelerini sınırlamaktadır [23]. İlaveten, nZVI atmosfere ve suya maruz kaldığında nZVI yüzeyinde sıklıkla oksit tabakası oluşmakta ve bu da nZVI'nın reaktivitesini ve stabilitesini önemli derecede azaltabilmektedir [24,25]. Bu dezavantajları çözmek için, nZVI partiküllerinin rektorit, bentonit, kaolin, zeolit, gözenekli karbon materyalleri, paligorskit, silika materyaller, reçine gibi çeşitli destek materyalleri üzerine yüklenilmesi önerilmektedir [26].

Klasik metot ile yürütülen optimizasyon çalışmalarında, prosese etki eden parametrelerden sadece biri değiştirilip diğer tüm parametreler belirli bir seviyede sabit tutulmaktadır. Proses parametrelerinin optimizasyonu için klasik metot çok sayıda deney yapılmasını gerektirmekte ve bu da çok zaman alıcı ve pahalı olmaktadır [27]. $\mathrm{Bu}$ metodun bir diğer dezavantajı ise parametreler arasında etkileşim etkilerinin belirlenememesidir [28]. Günümüzde, araştırmacılar tarafindan hazırlanan istatistiksel programlar sayesinde, optimum şartların belirlenmesi daha kısa sürede ve daha verimli bir şekilde az sayıda deney ile gerçekleştirilebilmektedir. Parametreler arasındaki ilişki düşük bir maliyetle oluşturulan matematiksel formüller kullanılarak kolayca tespit edilebilmektedir [29]. Çoklu değişkenlerin optimizasyonunda en yaygın şekilde kullanılan istatistiksel ve matematiksel programlardan biri cevap yüzey yöntemi (CYY)'dir [28]. CYY, iki veya daha fazla faktörün temel etkilerini ve etkileşimini tanımlayan istatistiksel bir yöntemdir [29]. CYY uygulayarak deneyler tasarlamak, modeller oluşturmak, istenen cevaplar için en uygun şartları belirlemek ve az sayıda deneyle arıtma verimini etkileyebilecek faktörlerin etkileşimini değerlendirmek mümkündür [30]. 
Bu çalışmada aktif karbon destekli nano boyutlu sıfır değerlikli demir (AC-nZVI) ile sulu ortamlardan fosfat giderimi araştırılmıştır. Çalışmada CYY kullanılarak AC-nZVI ile fosfat giderimi üzerinde başlangıç pH'ı, AC-nZVI miktarı, başlangıç fosfat konsantrasyonu ve temas süresi parametrelerinin etkileri incelenmiştir.

\section{MATERYAL VE METOT}

\section{A. AC-nZVI partiküllerini hazırlama}

Çalışmada kullanılan AC-nZVI partikülleri sıvı fazlı indirgeme metodu ile sentezlenmiştir. AC-nZVI sentezi Shi vd. [31]'nin çalışmasındaki prosedüre göre yürütülmüştür. Destek malzemesi olarak Merck marka ticari toz aktif karbon kullanılmıştır. AC-nZVI partikülleri 1:1 oranında aktif karbon/ $/ \mathrm{Fe}^{0}$ kütle oranı kullanılarak 4 boyunlu bir balonda azot gazı altında sentezlenmiştir. $9.66 \mathrm{~g}$ demir (III) klorür hekzahidrat $\left(\mathrm{FeCl}_{3} \cdot 6 \mathrm{H}_{2} \mathrm{O}\right)$ dört boyunlu balonda $50 \mathrm{~mL}$ 'lik etanol/su (4/1, v/v) karışımında çözdürüldükten sonra $2 \mathrm{~g}$ toz aktif karbon ilave edilmiş ve azotlu ortam altında 10 dakika sürekli olarak karıştırılmıştır. Daha sonra, azot gazı altında sürekli ve şiddetli bir şekilde karıştırılan bu karışıma saniyede 1-2 damla olacak şekilde sodyum borhidrür çözeltisi (3.54 g $\mathrm{NaBH}_{4} / 100 \mathrm{~mL}$ ) ilave edilmiştir. Sodyum borhidrür çözeltisinin tamamı ilave edildikten sonra karışım 20 dakika boyunca azotlu ortam altında karıştırılmıştır. Demir (III)'ün sıfır değerlikli demire indirgemesi Eşitlik 1'deki gibi gerçekleşmiştir [32]. Sentezlenen AC-nZVI partikülleri, vakum filtrasyonu kullanılarak hızlı bir şekilde $0.45 \mu \mathrm{m}$ filtreden geçirilmiş ve daha sonra $3 \mathrm{kez}$ etanol ile yıkanmıştır. Vakum filtrasyonu ile toplanan AC-nZVI partikülleri $60{ }^{\circ} \mathrm{C}$ 'de etüvde kurutulmuş ve kullanımdan önce azot gazı altında muhafaza edilmiştir.

$$
4 \mathrm{Fe}^{+3}+3 \mathrm{BH}_{4}^{-}+9 \mathrm{H}_{2} \mathrm{O} \rightarrow 4 \mathrm{Fe}^{0} \downarrow+3 \mathrm{H}_{2} \mathrm{BO}_{3}{ }^{-}+12 \mathrm{H}^{+}+6 \mathrm{H}_{2} \uparrow
$$

\section{B. Deneysel çalışma}

Çalışmada kullanılan fosfat çözeltileri Merck marka potasyum dihidrojen fosfat $\left(\mathrm{KH}_{2} \mathrm{PO}_{4}\right)$ kimyasalından hazırlanmıştır. Deneylerde fosfat çözeltisinin gerekli konsantrasyonları, $1000 \mathrm{mg} / \mathrm{L}$ olarak hazırlanan stok fosfat çözeltisi seyreltilerek hazırlanmıştır. Deneysel çalışma Gallenkamp marka sıcaklık kontrollü orbital bir çalkalayıcıda $25^{\circ} \mathrm{C}$ 'de $150 \mathrm{rpm}$ karıştırma hızında yürütülmüştür. Farklı konsantrasyonlarda $(5,16.25,27.5,38.75$ ve $50 \mathrm{mg} \mathrm{PO}$-P/L) $100 \mathrm{~mL}$ fosfat çözeltileri $250 \mathrm{~mL}$ 'lik erlenlere aktarılmış ve sülfürik asit $\left(\mathrm{H}_{2} \mathrm{SO}_{4}\right)$ ve sodyum hidroksit $(\mathrm{NaOH})$ çözeltileri kullanılarak fosfat çözeltileri belirli pH değerlerine (1, 2, 3, 4 ve 5) ayarlanmıştır. Daha sonra belli miktarlarda AC-nZVI $(0.20,0.35,0.50,0.65$ ve $0.80 \mathrm{~g} / \mathrm{L})$ erlenlere ilave edilip oda sicaklığında $\left(25^{\circ} \mathrm{C}\right) 150 \mathrm{rpm}$ 'de orbital çalkalayıcıda çalkalanmış ve MKD’ye göre belirlenmiş olan sürelerde erlenlerden sıvı karışım alınmıştır. AC-nZVI’ı sıvı fazdan ayırmak için, sıvı karışım Nüve marka (NF 800R) santrifüj cihazında $4000 \mathrm{rpm}$ hızında 5 dakika santrifüjlenmiştir. Santrifüj işleminden sonra duru fazın fosfat değeri Merck marka fosfat test kitleri kullanılarak Merck Spectroquant Nova 60 cihazı ile belirlenmiştir. Çözeltilerin pH'ı, Thermo Scientific marka (Orion Star A111) pH metre cihazı kullanılarak $\mathrm{H}_{2} \mathrm{SO}_{4}$ ve $\mathrm{NaOH}$ çözeltilerinin ilavesi ile ayarlanmıştır.

Fosfat giderim verimi aşağıdaki denkleme göre hesaplanmıştır:

$$
\text { Giderim verimi }(\%)=\frac{\left(C_{0}-C_{t}\right)}{C_{0}} \times 100
$$

Burada $\mathrm{C}_{0}(\mathrm{mg} / \mathrm{L})$ başlangıç $\mathrm{PO}_{4}-\mathrm{P}$ konsantrasyonu iken $\mathrm{C}_{\mathrm{t}}(\mathrm{mg} / \mathrm{L})$ herhangi bir $\mathrm{t}$ süresindeki $\mathrm{PO}_{4}-\mathrm{P}$ konsantrasyonudur.

\section{Deneysel dizayn}

Bu çalışmada, AC-nZVI ile fosfat giderimi üzerine çözelti pH’ı, AC-nZVI miktarı, başlangıç fosfat konsantrasyonu ve temas süresi gibi proses değişkenlerinin etkilerini belirlemek ve proses değişkenlerini optimize etmek için CYY'nin deneysel dizaynlarından biri olan MKD kullanılmıştır. Çözelti pH'1 $(A)$, AC-nZVI miktarı $(B)$, başlangıç fosfat konsantrasyonu $(C)$ ve temas süresi $(D)$ bağımsız değişkenler olarak, fosfat giderim verimi (\%) cevap olarak seçilmiştir. Bağımsız değişkenlerin her biri, beş farklı seviyede $(-2(\alpha),-1,0,1,+2(\alpha))$ incelenmiştir. Sistem tam faktöriyel ise beş seviyeli dizaynlarda $\alpha$ değeri Denklem (3)'e göre hesaplanmaktadır [33]. İstatistiksel hesaplama için, değişkenler Denklem (4)'e göre kodlanmıştır [34].

$$
\propto=\left\lfloor 2^{k}\right\rfloor^{1 / 4}
$$




$$
X_{i}=\frac{U_{i}-U_{1}^{0}}{\Delta U_{i}}
$$

Denklem (3)'teki, k faktör sayısıdır. Denklem (4)'teki, $X_{i}$ bağımsız değişkenin kodlanmış değeri, $U_{i}$ bağımsız değiş̧kenin gerçek değeri, $U_{I}^{o}$ merkezi noktadaki bağımsız değişkenin gerçek değeri ve $\Delta U_{i}$ adım değişim değeridir. Tüm deneyler, Design Expert7 (Stat-Ease, USA) istatistiksel yazılım programı ile tasarlanmıştır. Bu dört bağımsız değiş̧ken için MKD, 16 faktöriyel nokta, 8 eksenel nokta ve 6 merkez noktadan oluşan 30 deney serisi ile gerçekleştirilmiştir. Bağımsız değişkenler, deneysel aralıkları ve seviyeleri Tablo 1'de verilmiştir.

Bağımsız değişkenler ve cevap arasındaki matematiksel ilişki aşă̆ıdaki denklem ile ifade edilebilmektedir [28]:

$$
Y=b_{0}+\sum_{i=1}^{n} b_{i} X_{i}+\sum_{i=1}^{n} b_{i i} X_{i}^{2}+\sum_{i=1}^{n-1} \sum_{j=i+1}^{n} b_{i j} X_{i} X_{j}
$$

Bu denklemde, Y tahmin edilen cevap (fosfat giderim yüzdesi), $b_{0}$ bir sabit, $b_{i}, b_{i i}$ ve $b_{i j}$ strasiyla doğrusal, kuadratik ve etkileşimli etkiler için katsayısıdır, $X_{i}$ ve $X_{j}$ bağımsız değiş̧enlerdir, $n$ bağımsız değişken sayısıdır.

Tablo 1. Merkezi kompozit deneysel dizaynda bağımsız değişkenler, aralıkları ve değerleri

\begin{tabular}{lllllll}
\hline & \multicolumn{5}{c}{ Kodlanmış faktörlerin gerçek değerleri } \\
\cline { 2 - 7 } Bağımsız değişkenler & $\begin{array}{l}\text { Kodlanmış } \\
\text { sembol }\end{array}$ & -2 & -1 & 0 & +1 & -2 \\
\hline pH & $A$ & 1.00 & 2.00 & 3.00 & 4.00 & 5.00 \\
AC-nZVI miktarı (g/L) & $B$ & 0.20 & 0.35 & 0.50 & 0.65 & 0.80 \\
Başlangıç fosfat konsantrasyonu (mg P/L) & $C$ & 5.00 & 16.25 & 27.50 & 38.75 & 50.00 \\
Temas süresi (dakika) & $D$ & 5.00 & 33.75 & 62.50 & 91.25 & 120.00 \\
\hline
\end{tabular}

Bağımsız değişkenler ve elde edilen cevaplar arasındaki etkileşimi belirlemek amacıyla verilerin grafiksel analizinde varyans analizi (ANOVA) kullanılmışıır. Polinominal modelindeki uyum kalitesi determinasyon katsayısı $\left(\mathrm{R}^{2}\right)$ ile değerlendirilmiş ve istatistiksel önemi aynı programdaki F-testi ile doğrulanmıştır. Model terimleri \%95 güven seviyesine karşılık gelen P-değeri temel alınarak değerlendirilmiştir.

\section{BULGULAR VE TARTIȘMA}

AC-nZVI ile fosfat giderimi üzerinde başlangıç pH'ı, AC-nZVI miktarı, başlangıç fosfat konsantrasyonu ve temas süresi işletme parametrelerinin etkisi MKD kullanılarak araştıılmıştır. MKD kullanılarak oluşturulan bağımsız değiş̧kenlerin değerleri ve elde edilen deneysel sonuçlar Tablo 2'de verilmiştir.

Önerilen modelin güvenilirliğini değerlendirmek, bağımsız değişkenlerin ve etkileşimlerinin önemini belirlemek için varyans analizi (ANOVA) kullanılmış ve ANOVA sonuçları Tablo 3 'te verilmiştir. Modelin F değeri 7.40 ve $P$ değeri $>F$ değeri 0.0002 olarak belirlenmiştir. ANOVA değerlerinden de anlaşılacağ 1 gibi, verilerin modele uygunluğu anlamlıdır. Model denklemi ile deneysel sonuçlar arasındaki ilişkiyi tarif etmekte kullanılan yeterli hassasiyet değerinin 4'ten büyük olması istenmektedir [28]. Çalışmada 10.537 olarak belirlenen yeterli hassasiyet değeri, fosfat gideriminde model denkleminin deneysel sonuçların tahmininde hassas olduğuna işaret etmektedir. Ayrıca, geliştirilen kuadratik modelin uyum kalitesi, $\mathrm{R}^{2}$ değeri ile değerlendirilmektedir [35]. Fosfat giderimi için $\mathrm{R}^{2}$ değeri 0.8735 olarak belirlenmiştir. $\mathrm{R}^{2}$ değerlerinin 0.80 'den daha yüksek olması yapılan işlemlerin regresyon modeli ile açıklanabilir olduğunu göstermektedir [36]. $\mathrm{R}^{2}$ değerinin $\% 87.35$ olması, fosfat giderimi için toplam varyasyonun $\% 87.35$ 'inin bağımsız değişkenlere bağlı olduğu anlamına gelmekte ve sadece toplam varyasyonun \%12.65'inin modelle açıklanamadığını göstermektedir. Ayarlanmış $\mathrm{R}^{2}$ örnek boyutu ve modeldeki değişken sayısı için $\mathrm{R}^{2}$ değerini düzenlemektedir [28]. Bu çalışmada ayarlanmış $\mathrm{R}^{2}$ değeri 0.7554 olarak belirlenmiştir. Eğer model ve örnek boyutunda birçok değişken varsa ayarlanmış $\mathrm{R}^{2}$ değeri, determinasyon katsayısı $\mathrm{R}^{2}$ 'den daha küçük olabilir [28]. 
ANOVA analizinde $\mathrm{P}$ değerlerinin 0.05 'ten küçük olması model terimlerinin anlamlı olduğunu göstermekte, 0.1 'den büyük değerler ise model terimlerinin anlamlı olmadığını ifade etmektedir [37]. Tablo 3'e göz atıldığında, $A, B, A^{2}, B^{2}$ ve $D^{2}$ terimlerinin P değerleri 0.05 'ten küçük olduğundan dolayı bu terimler modelin önemli terimleridir. $\mathrm{pH}, \mathrm{AC}-\mathrm{nZVI}$ miktarı ve temas süresine ait $\mathrm{P}$ değerlerinin 0.1 'den büyük olmaması bu değişkenlerin lineer etkisinin önemli olduğunu ve bunlarda değişiklik yapıldığında fosfat giderim veriminin değişeceğini göstermektedir. pH ve AC-nZVI miktarının lineer etkisi ile birlikte ikinci dereceden etkisinin de önemli olduğu gözlenmiştir.

Tablo 2. Bağımsız değişkenleri gösteren deneysel dizayn matrisi ve sonuçları

\begin{tabular}{|c|c|c|c|c|c|c|c|c|c|}
\hline \multirow[t]{2}{*}{$\begin{array}{l}\text { Deney } \\
\text { No }\end{array}$} & \multicolumn{2}{|c|}{$\begin{array}{l}\text { Değişkenlerin } \\
\text { değerleri }\end{array}$} & \multicolumn{2}{|c|}{ kodlanmış } & \multicolumn{4}{|c|}{ Değişkenlerin kodlanmamış değerleri } & \multirow{2}{*}{$\begin{array}{l}\text { Cevap } \\
\begin{array}{l}\text { Fosfat } \\
\text { giderimi } \\
(\%)\end{array}\end{array}$} \\
\hline & $A$ & $B$ & $C$ & $D$ & $\mathrm{pH}(A)$ & $\begin{array}{l}\text { AC-nZVI } \\
\text { miktarı }(B)\end{array}$ & $\begin{array}{ll}\text { Başlangıç } & \text { fosfat } \\
\text { konsantrasyonu }(C)\end{array}$ & $\begin{array}{l}\text { Temas süresi } \\
(D)\end{array}$ & \\
\hline 1 & 2 & 0 & 0 & 0 & 5.00 & 0.50 & 27.50 & 62.50 & 64.34 \\
\hline 2 & 0 & 0 & 0 & 2 & 3.00 & 0.50 & 27.50 & 120.00 & 98.76 \\
\hline 3 & 1 & 1 & 1 & -1 & 4.00 & 0.65 & 38.75 & 33.75 & 62.76 \\
\hline 4 & -1 & 1 & -1 & 1 & 2.00 & 0.65 & 16.25 & 91.25 & 31.52 \\
\hline 5 & 1 & -1 & -1 & -1 & 4.00 & 0.35 & 16.25 & 33.75 & 60.25 \\
\hline 6 & 0 & 0 & 0 & 0 & 3.00 & 0.50 & 27.50 & 62.50 & 97.77 \\
\hline 7 & 1 & -1 & -1 & 1 & 4.00 & 0.35 & 16.25 & 91.25 & 71.43 \\
\hline 8 & 0 & 0 & -2 & 0 & 3.00 & 0.50 & 5.00 & 62.50 & 97.82 \\
\hline 9 & 1 & -1 & 1 & -1 & 4.00 & 0.35 & 38.75 & 33.75 & 42.45 \\
\hline 10 & -1 & -1 & 1 & 1 & 2.00 & 0.35 & 38.75 & 91.25 & 3.14 \\
\hline 11 & -2 & 0 & 0 & 0 & 1.00 & 0.50 & 27.50 & 62.50 & 0.00 \\
\hline 12 & -1 & -1 & -1 & -1 & 2.00 & 0.35 & 16.25 & 33.75 & 5.45 \\
\hline 13 & 0 & 0 & 0 & 0 & 3.00 & 0.50 & 27.50 & 62.50 & 97.21 \\
\hline 14 & 0 & 0 & 0 & 0 & 3.00 & 0.50 & 27.50 & 62.50 & 96.18 \\
\hline 15 & -1 & 1 & -1 & -1 & 2.00 & 0.65 & 16.25 & 33.75 & 20.61 \\
\hline 16 & 0 & 0 & 0 & 0 & 3.00 & 0.50 & 27.50 & 62.50 & 97.35 \\
\hline 17 & 0 & 0 & 0 & -2 & 3.00 & 0.50 & 27.50 & 5.00 & 41.18 \\
\hline 18 & -1 & 1 & 1 & -1 & 2.00 & 0.65 & 38.75 & 33.75 & 13.09 \\
\hline 19 & 0 & 0 & 0 & 0 & 3.00 & 0.50 & 27.50 & 62.50 & 97.20 \\
\hline 20 & 0 & 2 & 0 & 0 & 3.00 & 0.80 & 27.50 & 62.50 & 99.00 \\
\hline 21 & 1 & 1 & -1 & -1 & 4.00 & 0.65 & 16.25 & 33.75 & 83.23 \\
\hline 22 & 1 & -1 & 1 & 1 & 4.00 & 0.35 & 38.75 & 91.25 & 51.56 \\
\hline 23 & 1 & 1 & -1 & 1 & 4.00 & 0.65 & 16.25 & 91.25 & 89.07 \\
\hline 24 & -1 & 1 & 1 & 1 & 2.00 & 0.65 & 38.75 & 91.25 & 26.07 \\
\hline 25 & 0 & 0 & 0 & 0 & 3.00 & 0.50 & 27.50 & 62.50 & 96.84 \\
\hline 26 & -1 & -1 & 1 & -1 & 2.00 & 0.35 & 38.75 & 33.75 & 4.19 \\
\hline 27 & 0 & -2 & 0 & 0 & 3.00 & 0.20 & 27.50 & 62.50 & 42.50 \\
\hline 28 & 1 & 1 & 1 & 1 & 4.00 & 0.65 & 38.75 & 91.25 & 69.63 \\
\hline 29 & -1 & -1 & -1 & 1 & 2.00 & 0.35 & 16.25 & 91.25 & 7.27 \\
\hline 30 & 0 & 0 & 2 & 0 & 3.00 & 0.50 & 50.00 & 62.50 & 77.46 \\
\hline
\end{tabular}

Cevap ve bağımsız değişkenler arasındaki ampirik ilişki kodlanmış değerler cinsinden aşağıdaki şekilde elde edilmiştir: 
Fosfat giderimi $(\%)=+97.09+22.80 A+10.99 B-5.67 C+7.23 D+0.45 A B-3.74 A C-0.48 A D-$ $0.57 B C+1.01 B D-0.076 C D-20.39 A^{2}-10.75 B^{2}-6.53 C^{2}-10.94 D^{2}$

Burada $A, B, C$ ve $D$ bağımsız değişkenlerin (pH, AC-nZVI, başlangıç fosfat konsantrasyonu ve temas süresi) kodlanmış değerleridir. Model eşitliğindeki (Eşitlik 6) terimlerin önündeki pozitif işaret sinerjik etkiyi gösterirken, negatif işaret antagonistik etkiyi göstermektedir [27,28]. Eşitlik 6'da görüldüğü üzere, fosfat giderimi üzerinde $\mathrm{pH}(A)$, AC-nZVI miktarı $(B)$ ve temas süresi pozitif etkiye, başlangıç fosfat konsantrasyonu $(C)$ ise negatif etkiye sahip olmuştur. ANOVA analizi sonucunda parametrelere ait katsayılar ve standart hatalar Tablo 4'te verilmiştir.

Tablo 3. Kuadratik modelin varyans analizi (ANOVA) sonuçları

\begin{tabular}{|c|c|c|c|c|c|}
\hline Model Kaynakları & Kareler toplamı & Serbestlik derecesi & Ortalama kare & F-değeri & P-değeri $>F$ \\
\hline Model & 32290.44 & 14 & 2306.46 & 7.40 & 0.0002 \\
\hline$A$ & 12471.14 & 1 & 12471.14 & 39.99 & $<0.0001$ \\
\hline$B$ & 2901.14 & 1 & 2901.14 & 9.30 & 0.0081 \\
\hline$C$ & 771.01 & 1 & 771.01 & 2.47 & 0.1367 \\
\hline$D$ & 1253.54 & 1 & 1253.54 & 4.02 & 0.0634 \\
\hline$A B$ & 3.18 & 1 & 3.18 & 0.010 & 0.9209 \\
\hline$A C$ & 223.88 & 1 & 223.88 & 0.72 & 0.4101 \\
\hline$A D$ & 3.72 & 1 & 3.72 & 0.012 & 0.9145 \\
\hline$B C$ & 5.28 & 1 & 5.28 & 0.017 & 0.8982 \\
\hline$B D$ & 16.34 & 1 & 16.34 & 0.052 & 0.8220 \\
\hline$C D$ & 0.092 & 1 & 0.092 & $2.935 \times 10^{-4}$ & 0.9866 \\
\hline$A^{2}$ & 11408.73 & 1 & 11408.73 & 36.59 & $<0.0001$ \\
\hline$B^{2}$ & 3169.53 & 1 & 3169.53 & 10.16 & 0.0061 \\
\hline$C^{2}$ & 1168.57 & 1 & 1168.57 & 3.75 & 0.0720 \\
\hline$D^{2}$ & 3285.56 & 1 & 3285.56 & 10.54 & 0.0054 \\
\hline
\end{tabular}

$\mathrm{R}^{2}=0.8735$, Ayarlanmıs $\mathrm{R}^{2}=0.7554$ 
Tablo 4. ANOVA analizi sonucunda parametrelere ait katsayılar ve standart hatalar

\begin{tabular}{lll}
\hline Faktör & Katsay1 & Standart hata \\
\hline Kayma & 97.09 & 7.21 \\
$A$ & 22.80 & 3.60 \\
$B$ & 10.99 & 3.60 \\
$C$ & -5.67 & 3.60 \\
$D$ & 7.23 & 3.60 \\
$A B$ & 0.45 & 4.41 \\
$A C$ & -3.74 & 4.41 \\
$A D$ & 0.48 & 4.41 \\
$B C$ & -0.57 & 4.41 \\
$B D$ & 1.01 & 4.41 \\
$C D$ & -0.076 & 4.41 \\
$A^{2}$ & -20.39 & 3.37 \\
$B^{2}$ & -10.75 & 3.37 \\
$C^{2}$ & -6.53 & 3.37 \\
$D^{2}$ & -10.94 & 3.37 \\
\hline
\end{tabular}

MKD’ye dayalı CYY'nin uygulanması araştırmacıların, önemli faktörleri optimize etmesine ve cevap hakkında önemli bilgiler sağlamasına yardımcı olmaktadır [27]. Bu nedenle, bağımlı değiş̧en üzerinde bağımsız değişkenlerin etkilerini ve bunların etkileşimlerini daha iyi anlayabilmek için, ölçülen cevaplar için üç boyutlu (3D) cevap yüzey grafikleri kuadratik modele dayanarak oluşturulmuştur. 3D cevap yüzey grafikleri genellikle regresyon denkleminin grafiksel gösterimidir [38]. Fosfat giderim verimi üzerine bağımsız değişkenlerin etkileri üç boyutlu (3D) cevap yüzey grafikleri ile Şekil la-f'de verilmiştir.

AC-nZVI ile fosfat giderim verimi üzerinde pH ve AC-nZVI'nın etkisi Şekil 1a'da sunulmuştur. Ortam pH'1; adsorbentin yüzey yükünü, iyonlaşma derecesini ve adsorbat türlerinin özelliklerini değiştirebildiği için adsorpsiyonu kuvvetli şekilde etkileyen önemli bir parametredir [39]. Bilindiği üzere mevcut fosfat türleri sulu çözeltinin pH'ına bağlı olarak suda $\mathrm{H}_{2} \mathrm{PO}_{4}{ }^{-}, \mathrm{HPO}_{4}{ }^{-2}$ ve $\mathrm{PO}_{4}{ }^{-3}$ gibi farklı iyonik formlarda bulunabilmektedir. $\mathrm{pH}$ değeri 2.1'den düşük olduğunda $\mathrm{H}_{3} \mathrm{PO}_{4}$, $\mathrm{pH} 2.1$ ve 7.2 arasında olduğunda $\mathrm{H}_{2} \mathrm{PO}_{4}^{-}$, pH 7.2 ve 12.3 arasında olduğunda $\mathrm{HPO}_{4}{ }^{-2}, \mathrm{pH} 12.3$ 'ten yüksek olduğunda $\mathrm{PO}_{4}^{-3}$ baskın olan tür olmaktadır [40]. Şekil 1a incelendiğinde, yüksek giderim verimlerinin yaklaşık pH 3.0-3.6 aralığında sağlandığı görülmektedir. $\mathrm{Bu} \mathrm{pH}$ aralığında gözlenen yüksek giderim veriminin nedeni; ortama eklenen $\mathrm{H}^{+}$iyonundan dolayı $\mathrm{AC}-\mathrm{nZVI}$ yüzeyinin pozitif yüklenmiş olması ve negatif yüklü fosfat iyonu ile arasındaki çekim kuvvetine bağlanabilir. pH 3'ün altında gözlenen düşük giderim verimi çözeltide nZVI'nın çözünmesinden dolayı, fosfat giderimi için mevcut yüzey alanının yetersiz olması ile ilgili olabilir [41]. $27.50 \mathrm{mg} \mathrm{PO} 4-\mathrm{P} / \mathrm{L}$ fosfat konsantrasyonu, $0.5 \mathrm{~g} / \mathrm{L}$ AC-nZVI miktarı ve 62.50 dakika temas süresi şartlarında $\mathrm{pH}$ 1'de fosfat giderimi sağlanmamıştır (Tablo 2). Bu durum, bu pH'da nZVI partiküllerinin çözelti içinde hızlı bir şekilde tamamen çözünmesinden dolayı nZVI partiküllerinin çözeltide bulunmamasına bağlanabilir. Ayrıca bu sonuç, fosfat gideriminde AC-nZVI materyalinde mevcut olan nZVI'nın sadece etkili olduğunu, aktif karbonun etkili olmadığını göstermiştir. Bu durumda, aktif karbonun sadece destek malzemesi görevini üstlendiğini söyleyebiliriz. Yaklaşık olarak $0.50 \mathrm{~g} / \mathrm{L}$ 'e kadar AC-nZVI miktarındaki artış ile fosfat giderim veriminin arttığı görülmektedir. Bu durum, AC-nZVI miktarının artışı ile hem AC-nZVI yüzey alanın artması hem de kullanılabilir aktif bölge sayısının artmasına bağlanmaktadır [42]. $0.50 \mathrm{~g} / \mathrm{L}$ 'den fazla ACnZVI miktarında giderim verimleri birbirine yakın olarak gözlenmiştir. Bunun nedeni, ortamdaki fosfatın büyük çoğunluğunun adsorplanmış olmasına ve ortamda yeteri miktarda fosfatın bulunmamasına bağlanabilir. Şekil 1a'da görüldüğü üzere, fosfat giderim verimi üzerinde hem $\mathrm{pH}$ hem de AC-nZVI miktarı etkili olmuştur. Fakat çözelti pH'1 AC-nZVI miktarına göre daha etkili olmuştur.

AC-nZVI ile fosfat giderim verimi üzerinde $\mathrm{pH}$ ve fosfat konsantrasyonunun etkisi Şekil $1 \mathrm{~b}$ 'de gösterilmiş̧tir. Şekilden görüldüğ̈̈ üzere, yüksek giderim verimleri yaklaşık pH 3.0-3.6 aralığında sağlanmıştır. Yaklaşık olarak $27.50 \mathrm{mg} / \mathrm{L}$ fosfat konsantrasyonuna kadar fosfat giderim verimi hemen hemen birbirine yakın olarak gözlenmiştir. $27.50 \mathrm{mg} / \mathrm{L}$ 'nin üzerindeki konsantrasyonlarda verim gittikçe azalmaktadır. $27.50 \mathrm{mg} / \mathrm{L}$ 'e 
kadar yüksek giderim veriminin gözlenmesinin nedeni fosfatın adsorblanması için ortamda yeteri kadar AC-nZVI yüzey aktif bölgelerinin mevcut olmasıdır.
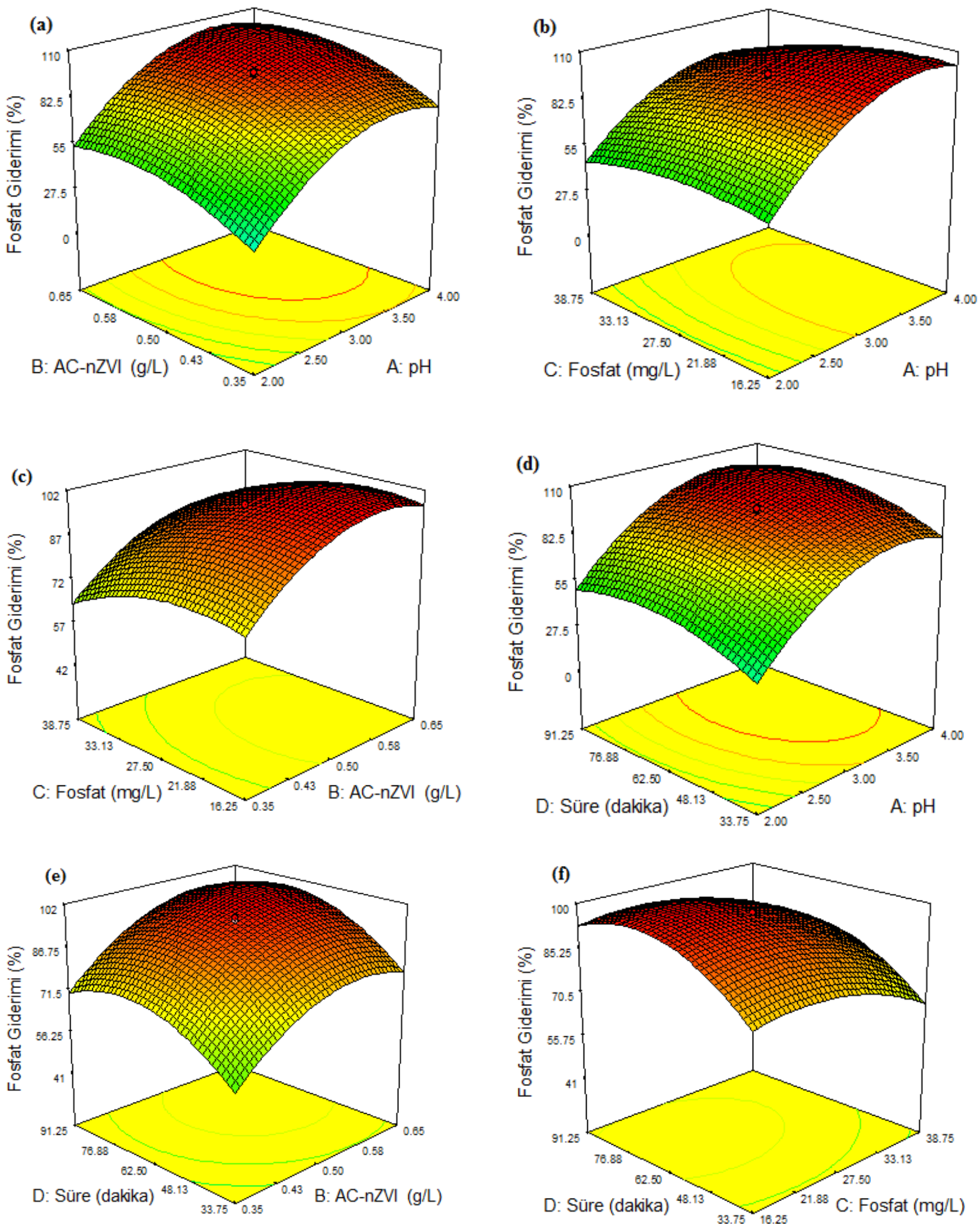

Şekil 1. Fosfat giderim veriminin üç boyutlu (3D) cevap yüzey grafikleri: a) pH ve AC-nZVI miktarının etkisi; b) pH ve başlangıç fosfat konsantrasyonunun etkisi; c) AC-nZVI miktarı ve başlangıç fosfat konsantrasyonunun etkisi; d) pH ve temas süresinin etkisi; e) AC-nZVI miktarı ve temas süresinin etkisi; f) Başlangıç fosfat konsantrasyonu ve temas süresinin etkisi 
Yüksek fosfat konsantrasyonlarında, AC-nZVI yüzey aktif alanlarının çözeltideki fosfat moleküllerine oranının düşük olması daha düşük giderim verimi sağlamaktadır [37]. Yüksek fosfat konsantrasyonlarında, verimin azalmasının nedeni fosfatın adsorplanması için ortamda AC-nZVI yüzeyindeki aktif bölgelerin sınırlı olmasına ve adsorbat molekülleri arasındaki rekabetin artmasına bağlanabilir [42].

AC-nZVI ile fosfat giderimi üzerinde AC-nZVI ve fosfat konsantrasyonun etkisi Şekil 1c'da gösterilmiştir. Şekil 1c'e bakıldığında, AC-nZVI miktarının artışı ile fosfat giderim verimi artmıştır. Belli bir konsantrasyonun (yaklaşık $27.50 \mathrm{mg} / \mathrm{L}$ ) üzerinde fosfat konsantrasyonundaki artış ile giderim verimi azalmıştır. Artan adsorbent dozajı ile AC-nZVI üzerine fosfatın adsorpsiyonu için daha fazla aktif yüzey alanları sonuç olarak daha fazla bağlanma alanları sağlandığı için artan AC-nZVI ile verim artmıştır. Diğer taraftan, artan fosfat konsantrasyonu ile AC-nZVI yüzeyindeki adsorpsiyon bölgeleri doygun hale geldiği için giderim verimi azalmıştır [29].

Temas süresinin pH, AC-nZVI ve başlangıç fosfat konsantrasyonu ile etkileri sırasıyla Şekil 1d, Şekil 1e ve Şekil 1f'de verilmiştir. Şekil 1d'den görüldüğü üzere, düşük pH değerinden $\mathrm{pH} 3$ değerine kadar pH'daki artış ve yaklaşık 62.50 dakikaya kadar temas süresindeki artış ile fosfat giderim verimi artmıştır. pH ile kıyaslandığında temas süresi fosfat giderim verimi üzerinde daha az etkili olduğu görünmektedir. pH 3, 0.50 g/L AC-nZVI ve $27.50 \mathrm{mg} / \mathrm{L}$ fosfat konsantrasyonu şartlarında $5,62.50$ ve 120 dakikalık temas sürelerinde giderim verimleri sırasıyla \%41.2, \%97.2 ve \%98.8 olarak bulunmuştur (Tablo 2). İlk 5 dakikalık temas süresinde gözlenen \% 41 'lik verim başlangıç aşamasında adsorpsiyonun hızlı gerçekleştiğini göstermektedir. Adsorpsiyon sürecinin başlangıcında gerçekleşen hızlı adsorpsiyonun nedeni, adsorpsiyonun başlangıcında AC-nZVI yüzeyinde çok sayıda boş aktif bölgelerin bulunmasıdır [42]. Ancak, zaman geçtikçe, bu bölgeler fosfat molekülleri tarafından işgal edilmiş ve dengeleme sürecinden sonra giderim verimi sabit kalmıştır. Hem kullanılabilir boş aktif bölgelerin sayısının azalması [42] hem de ortamdaki fosfatın büyük çoğunluğunun adsorplanmış olmasından dolayı 62.50 dakikalık temas süresinden sonra giderim verimi birbirine yakın olarak gözlenmiştir. Şekil 2e incelendiğinde, yaklaşık olarak 62.50 dakikaya kadar artan temas süresi ile giderim veriminin arttığı ve yaklaşık 0.50-0.60 g/L'e kadar artan AC-nZVI miktarı ile giderim verimi artmıştır. AC-nZVI miktarının arttırılması ile hem AC-nZVI yüzey alanı hem de kullanılabilir aktif bölge sayısı arttığı için verim artmaktadır [42]. Şekil 2f incelendiğinde, artan temas süresi ile giderim veriminin $\operatorname{arttığ} 1$ ve artan fosfat konsantrasyonu ile giderim veriminin azaldı $\breve{1}$ görülmektedir. Fosfat konsantrasyonun artması ile fosfat giderim veriminin azalmasının sebepleri aktif karbon yüzeyindeki aktif bölgelerin sınırlı olması ve adsorbat molekülleri arasındaki rekabetin artmasıdır [42]. Düşük fosfat konsantrasyonlarında, fosfatın adsorbent alanlarına oranının düşük olması daha yüksek giderim verimi sağlamaktadır. Daha yüksek konsantrasyonlarda, fosfat giderim veriminin azalması, adsorpsiyon bölgelerinin doygunluğa ulaşmasından kaynaklanmaktadır [27,29].

AC-nZVI kullanılarak fosfat giderimi için maksimum giderim verimini veren optimum deneysel şartlar Desing Expert'in desirability fonksiyonu kullanılarak belirlenmiştir. Maksimum fosfat giderimi (\%100) için optimum şartlar pH 3.09, AC-nZVI miktar1 $0.59 \mathrm{~g} / \mathrm{L}$, fosfat konsantrasyonu $30.69 \mathrm{mg} / \mathrm{L}$ ve temas süresi 66.58 dakika olarak belirlenmiştir. Literatürde, nZVI ile fosfat gideriminin rapor edildiği bir çalışmada da en yükssek fosfat giderim verimi $\mathrm{pH} 3$ değerinde elde edilmiştir [40].

Optimizasyon sonucunun doğruluğunu ortaya koymak için, bu optimum şartlarda deneysel çalışma yapılmış ve fosfat giderim verimi $\% 98.8$ olarak elde edilmiştir. Bu sonucun \%95 güven aralığında olduğu görülmektedir. $\mathrm{Bu}$ durumda, model çıktılarının deneysel olarak elde edilen sonuçlar ile uyumlu olduğu söylenebilir.

\section{SONUÇLAR}

Bu çalışmada, AC-nZVI ile sulu ortamlardan fosfat giderimi incelenmiştir. CYY kullanılarak pH, ACnZVI, fosfat konsantrasyonu ve temas süresi parametrelerinin etkisi ve optimum şartlar belirlenmiştir. Design Expert yazılımı kullanılarak bu dizayndan ikinci dereceden bir model elde edilmiştir. Bu modele göre fosfat giderimi üzerinde $\mathrm{pH}, \mathrm{AC}$-nZVI miktarı ve temas süresi pozitif etkiye, başlangıç fosfat konsantrasyonu ise negatif etkiye sahip olmuştur. AC-nZVI ile sulu ortamlardan fosfat giderimi için optimum şartlar pH 3.09, AC-nZVI miktar1 $0.59 \mathrm{~g} / \mathrm{L}$, fosfat konsantrasyonu $30.69 \mathrm{mg} / \mathrm{L}$ ve temas süresi 66.58 dakika olarak belirlenmiştir. Bu araştırma AC-nZVI'nın fosfat gideriminde etkili bir materyal olduğunu göstermektedir. Yüksek giderim verimi, AC-nZVI'nın, yüksek fosfat konsantrasyonu içeren atıksulardan fosfatı giderme potansiyeline sahip olduğunu göstermektedir. $\mathrm{Bu}$ araştırma, atıksulardan başka kirleticilerin adsorpsiyonu için de genişletilebilir. 


\section{KAYNAKLAR}

[1] Zhang, C., Li, Y., Wang, F., Yu, Z., Wei, J., Yang, Z., Ma, C., Li, Z., Xu, Z., \& Zeng, G. (2017). Performance of magnetic zirconium-iron oxide nanoparticle in the removal of phosphate from aqueous solution. Applied Surface Science, 396, 1783-1792.

[2] Belelli, P. G., Fuente, S. A., \& Castellani, N. J. (2014). Phosphate adsorption on goethite and Al-rich goethite. Computational Materials Science, 85, 59-66.

[3] Boeykens, S. P., Piol, M. N., Legal, L. S., Saralegui, A. B., \& Vázquez, C. (2017). Eutrophication decrease: phosphate adsorption processes in presence of nitrates. Journal of Environmental Management, 203, 888895.

[4] Almeelbi, T., \& Bezbaruah, A. (2012). Aqueous phosphate removal using nanoscale zero-valent iron. Journal of Nanoparticle Research, 14, 900.

[5] Attour, A., Touati, M., Tlili, M., Amor, M. B., Lapicque, F., \& Leclerc, J.-P. (2014). Influence of operating parameters on phosphate removal from water by electrocoagulation using aluminum electrodes. Separation and Purification Technology, 123, 124-129.

[6] El Bouraie, M., \& Masoud, A. A. (2017). Adsorption of phosphate ions from aqueous solution by modified bentonite with magnesium hydroxide $\mathrm{Mg}(\mathrm{OH})_{2}$. Applied Clay Science, 140, 157-164.

[7] Franco, D., Lee, J., Arbelaez, S., Cohen, N., \& Kim, J.-Y. (2017). Removal of phosphate from surface and wastewater via electrocoagulation. Ecological Engineering, 108, 589-596.

[8] Chen, D., Gao, B., Wang, H., \& Yang, K. (2016). Effective removal of high concentration of phosphate by starch-stabilized nanoscale zerovalent iron (SNZVI). Journal of the Taiwan Institute of Chemical Engineers, 61, 181-187.

[9] Van der Houwen, J., \& Valsami-Jones, E. (2001). The application of calcium phosphate precipitation chemistry to phosphorus recovery: the influence of organic ligands. Environmental Technology, 22(11), 1325-1335.

[10] Peng, Y. Z., Wang, X. L., \& Li, B. K. (2006). Anoxic biological phosphorus uptake and the effect of excessive aeration on biological phosphorus removal in the A(2)O Process. Desalination, 189(1-3), 155-164.

[11] Ajmal, Z., Muhmood, A., Usman, M., Kizito, S., Lu, J., Dong, R., \& Wu, S. (2018). Phosphate removal from aqueous solution using iron oxides: adsorption, desorption and regeneration characteristics. Journal of Colloid and Interface Science, 528, 145-155.

[12] Zhang, Q., Liu, H., Chen, T., Chen, D., Li, M., \& Chen, C. (2017). The synthesis of NZVI and its application to the removal of phosphate from aqueous solutions. Water Air Soil Pollution, 228(9), 321.

[13] Yan, L. G., Xu, Y. Y., Yu, H. Q., Xin, X. D., Wei, Q., \& Du, B. (2010). Adsorption of phosphate from aqueous solution by hydroxy-aluminum, hydroxy-iron and hydroxy-iron-aluminum pillared bentonites. Journal of Hazardous Materials, 179(1-3), 244-250.

[14] Chitrakar, R., Tezuka, S., Sonoda, A., Sakane, K., Ooi, K., \& Hirotsu, T. (2006). Phosphate adsorption on synthetic goethite and akaganeite. Journal of Colloid and Interface Science, 298(2), 602-608.

[15] Yue, Q. Y., Zhao, Y. Q., Li, Q., Li, W. H., Gao, B. Y., Han, S. X., Qi, Y. F., \& Yu, H. (2010). Research on the characteristics of red mud granular adsorbents (RMGA) for phosphate removal. Journal of Hazardous Materials, 176(1-3), 741-748.

[16] Hussain, S., Aziz, H. A., Isa, M. H., Ahmad, A., Van Leeuwen, J., Zou, L., Beecham, S., \& Umar, M. (2011). Orthophosphate removal from domestic wastewater using limestone and granular activated carbon. Desalination, 271(1-3), 265-272. 
[17] Eljamal, O., Khalil, A. M. E., Sugihara, Y., \& Matsunaga, N. (2016). Phosphorus removal from aqueous solution by nanoscale zero valent iron in the presence of copper chloride. Chemical Engineering Journal, 293, 225-231.

[18] Lowry, G.V., \& Johnson, K. M. (2004). Congener-specific dechlorination of dissolved pcbs by microscale and nanoscale zerovalent iron in a water/methanol solution. Environmental Science and Technology, 38(19), 5208-5216.

[19] Lavine, B.K., Auslander, G., \& Ritter, J. (2001). Polarographic studies of zero valent iron as a reductant for remediation of nitroaromatics in the environment. Microchemical Journal, 70(2), 69-83.

[20] Hanay, Ö., \& Türk, H. (2015). Comprehensive evaluation of adsorption and degradation of tetracycline and oxytetracycline by nanoscale zero-valent iron. Desalination and Water Treatment, 53(7), 1986-1994.

[21] Sohrabi, M. R., Amiri, S., Masoumi, H. R. F., \& Moghri, M. (2014). Optimization of Direct Yellow 12 dye removal by nanoscale zero-valent iron using response surface methodology. Journal of Industrial and Engineering Chemistry, 20(4), 2535-2542.

[22] Boparai, H. K., Joseph, M., \& O’Carroll, D. M. (2011). Kinetics and thermodynamics of cadmium ion removal by adsorption onto nano zerovalent iron particles. Journal of Hazardous Materials, 186(1), 458-465.

[23] Arancibia-Miranda, N., Baltazar, S. E., García, A., Mũnoz-Lira, D., Sepúlveda, P., Rubio, M. A., \& Altbir, D. (2016). Nanoscale zero valent supported by Zeolite and Montmorillonite: Template effect of the removal of lead ion from an aqueous solution. Journal of Hazardous Materials, 301, 371-380.

[24] Diao, Z.-H., Xu, X.-R., Jiang, D., Kong, L.-J., Sun, Y.-X., Hu, Y.-X., Hao, Q.-W., \& Chen, H. (2016). Bentonite-supported nanoscale zero-valent iron/persulfate system for the simultaneous removal of $\mathrm{Cr}(\mathrm{VI})$ and phenol from aqueous solutions. Chemical Engineering Journal, 302, 213-222.

[25] Wang J., Liu G., Zhou C., Li T., \& Liu J. (2014). Synthesis, characterization and aging study of kaolinitesupported zero-valent iron nanoparticles and its application for Ni(II) adsorption. Materials Research Bulletin, 60, 421-432.

[26] Sun, Z., Zheng, S., Ayoko, G.A., Frost, R.L., \& Xi, Y. (2013). Degradation of simazine from aqueous solutions by diatomite-supported nanosized zero-valent iron composite materials. Journal of Hazardous Materials, 263, 768-777.

[27] Abbasi, M., \& Habibi, M. M. (2016). Optimization and characterization of Direct Blue 71 removal using nanocomposite of Chitosan-MWCNTs: Central composite design modeling. Journal of the Taiwan Institute of Chemical Engineers, 62, 112-121.

[28] Tanyol, M. (2017). Malahit yeşili içeren atıksuların fenton oksidasyon prosesi ile renk gideriminde işletme parametrelerinin optimizasyonu. Fırat Üniversitesi Mühendislik Bilimleri Dergisi, 29(1), 183-191.

[29] Torgut, G., Tanyol, M., Biryan, F., Pihtili, G., \& Demirelli, K. (2017). Application of response surface methodology for optimization of Remazol Brilliant Blue R removal onto a novel polymeric adsorbent. Journal of the Taiwan Institute of Chemical Engineers, 80, 406-414.

[30] Muhamad, M. H., Abdullah, S. R. S., Mohamad, A. B., Rahman, R. A., \& Kadhum, A. A. H. (2013). Application of response surface methodology (RSM) for optimisation of COD, $\mathrm{NH}_{3}-\mathrm{N}$ and 2,4-DCP removal from recycled paper wastewater in a pilot-scale granular activated carbon sequencing batch biofilm reactor (GAC-SBBR). Journal of Environmental Management, 121, 179-190.

[31] Shi, L.-n., Zhang, X., \& Chen, Z.-1. (2011). Removal of chromium (VI) from wastewater using bentonitesupported nanoscale zero-valent iron. Water Research, 45(2), 886-892.

[32] Fan, J., Guo, Y., Wang, J., \& Fan, M. (2009). Rapid decolorization of azo dye methyl orange in aqueous solution by nanoscale, zerovalent iron particles. Journal of Hazardous Materials, 166(2-3), 904-910. 
[33] Değirmencioğlu, A., \& Yazg1, A. (2006). Tepki yüzeyleri metodolojisi optimizasyon esaslı çalışmalara ilişkin teorik esaslar ve tarımsal mekanizasyon uygulamaları. Tarım Makinaları Bilimi Dergisi, 2(2), 111115 .

[34] Elibol, M., \& Ozer, D. (2002). Response surface analysis of lipase production by freely suspended Rhizopus Arrhizus. Process Biochemistry, 38(3), 367-372.

[35] Singh, A. K., \& Singh, K. P. (2018). Optimization of phosphate removal from aqueous solution using activated carbon supported zero-valent iron nanoparticles: application of RSM approach. Applied Water Science, 8, 226.

[36] Kasap, T. (2017). Kağıt endüstrisi atıksularının peroksit ilaveli elektrokoagülasyon yöntemi ile arıtımında cevap yüzey yöntemi kullanılarak proses optimizasyonu, Yüksek Lisans Tezi, Yıldız Teknik Üniversitesi, Fen Bilimleri Enstitüsü, İstanbul.

[37] Arslan-Alaton, I., Tureli, G., \& Olmez-Hanci, T. (2009). Treatment of azo dye production wastewaters using Photo-Fenton-like advanced oxidation processes: Optimization by response surface methodology. Journal of Photochemistry and Photobiology A: Chemistry, 202(2-3), 142-153.

[38] Tepe, O. (2018). Adsorption of Remazol Brillant Green 6B (RBG 6B) on chitin: process optimization using response surface methodology. Global NEST Journal, 20(2), 257-268.

[39] Iqbal, M., Iqbal, N., Bhatti, I.A., Ahmad, N., \& Zahid, M. (2016). Response surface methodology application in optimization of cadmium adsorption by shoe waste: A good option of waste mitigation by waste. Ecological Engineering, 88, 265-275.

[40] Wen, Z., Zhang, Y., \& Dai, C. (2014). Removal of phosphate from aqueous solution using nanoscale zerovalent iron (nZVI). Colloids and Surfaces A: Physicochemical and Engineering Aspects, 457, 433-440.

[41] Shu, H. Y., Chang, M. C., Chen, C. C., \& Chen, P. E. (2010). Using resin supported nano zero-valent iron particles for decoloration of Acid Blue 113 azo dye solution. Journal of Hazardous Materials, 184(1-3), 499-505.

[42] Baytar, O., Ceyhan, A. A. \& Şahin, Ö. (2018). İğde çekirdeğinden elde edilen aktif karbon kullanılarak sulu çözeltilerden $\mathrm{Pb}(\mathrm{II})$ adsorpsiyonun incelenmesi: İzoterm ve kinetik. Bitlis Eren Üniversitesi Fen Bilimleri Dergisi, 7 (2), 256-267. 